\title{
PENGARUH VARIASI SPRING DAN MASSA ROLLER CONTINUOUSLY VARIABLE TRANSMISSION (CVT) TERHADAP PERFORMA HONDA VARIO 125CC PGM FI
}

\author{
Yanwar Dwi Prasetyo ${ }^{1}$ dan Suwahyo \\ 1,2)Pendidikan Teknik Otomotif, Jurusan Teknik Mesin, Fakultas Teknik, \\ Universitas Negeri Semarang \\ Anwarprasetyo06@gmail.com
}

\begin{abstract}
ABSTRAK: Penelitian ini bertujuan untuk mengetahui perbedaan performa mesin dengan variasi spring (pegas pulley) dan massa roller CVT pada sepeda motor automatic. Objek penelitian ini adalah peforma pada Honda Vario 125cc PGM FI tahun 2013. Performa mesin yang diperoleh berupa nilai torsi, dan daya dengan pengambilan data menggunakan dynotest. Penelitian ini menggunakan metode eksperimen dan metode analisis secara deskriptif. Hasil penelitian menunjukkan ada perbedaan performa mesin, diketahui bahwa pegas CVT dengan jarak pitch coil 26,7mm mampu menghasilkan daya kendaraan terbesar dengan menggunakan roller 9 gram pada kecepatan menengah 5000 rpm senilai 10,8hp dan pegas dengan jarak pitch coil 27,3mm menghasilkan daya kendaraan terbesar dengan menggunakan roller $10 \mathrm{gram}$ pada kecepatan menengah 5000rpm senilai 10,6hp. RollerCVT dengan berat 18 gram mampu menghasilkan torsi maksimum pada penggunaan pegas $26,7 \mathrm{~mm}$ kecepatan 2500rpm senilai 23,55 N.m, maupun dengan menggunakan pegas $27,3 \mathrm{~mm}$ torsi maksimum terjadi juga pada kecepatan 2500rpm senilai 24.50 N.m. Penelitian ini menyimpulkan bahwa pegas dengan jarak pitch coil $26,7 \mathrm{~mm}$ dan roller 9 gram yang mampu menghasilkan gaya dorong kendaraan terbesar pada kecepatan menengah 5000rpm lebih cocok digunakan untuk berakselerasi di jalan kota.
\end{abstract}

Kata kunci: roller CVT, spring CVT, performa, dan transmisi

\section{PENDAHULUAN}

Perkembangan teknologi yang pesat dewasa ini menimbulkan dampak yang besar pada dunia teknologi khususnya dunia otomotif. Banyaknya permintaan konsumen dalam penggunaan sepeda motor ini produsen sepeda motor berlomba-lomba dan berinovasi melucurkan sepada motor bertransmisi otomatis atau yang sering disebut dengan motor matic. Penggunaan transmisi otomatis memungkinkan motor dapat melaju dengan stabil dan kecepatan rendah kekecepatan tinggi tanpa memindahkan gigi transmisi seperti halnya pada sepeda motor 4 tak atau 2 tak yang bertransmisi manual.

Menurut Wahyu Hidayat (2015: 45) "Motor jenis matic memanfaatkan system pemindah daya otomatis mengikuti RPM mesin, mempunyai susunan komponen mekanisnya adalah sebagai berikut: motor bensin, roda variator - vbelt, kopling radial otomatis langsung ke poros penggerak roda". Menurut Adityas et al., (2012: 65) jika diambil contoh perbandingan dengan motor bebek yang memiliki ruang bakar 
yang sama contohnya Yamaha vega ZR dan Mio sporty yaitu $113,7 \mathrm{cc}$, vega ZR memiliki torsi maksimum $8,3 \mathrm{~N} . \mathrm{m}$ pada $4.500 \mathrm{rpm}$ sedangkan Mio sporty mempunyai torsi maksimum $7,84 \mathrm{~N} . \mathrm{m}$ pada $7.000 \mathrm{rpm}$.

Perbedaan motor matic dengan motor manual pada umumnya adalah system transmisi dan pemindahan gaya. Pada motor manual system transmisi dipindahkan secara manual yaitu dengan gigi rasio, hal ini memungkinkan motor manual untuk mencapai top speed, dan pemindah gaya dari mesin keroda menggunakan sprocket dan rantai roda, sedangkan "pada motor matic untuk mencapai top speed tidak perlu memindahkan transmisi, karena putaran mesin langsung digunakan untuk menggerakkan puli primerskunder-tranmisi-roda, sedangkan untuk pemindah gaya dari mesin keroda menggunakan drive belt dan puli" (Dharma et al., 2013).

Besar kecilnya gaya tekan roller sentrifugal terhadap sliding sheave ini berbanding lurus dengan massa roller sentrifugal dan putaran mesin. Pada puli sekunder "besar kecilnya gaya tekan sliding sheave terhadap pegas berbanding lurus dengan konstanta pegas, semakin besar nilai konstanta pegas maka semakin besargaya tekan sliding sheave terhadap pegas pada pulley sekunder sehingga pergerakan pulley menjadi kecil" (Dharma et al., 2013). Tujuan dari penelitian ini adalah untuk mengetahui pengaruh variasi spring pulley dan massa roller terhadap peforma honda vario 125cc PGM FI.

\section{METODE}

Penelitian ini menggunakan metode penelitian eksperimen dengan teknik analisis deskriptif. Data penelitian diperoleh dengan melakukan pengujian pada obyek penelitian yang meliputi torsi dan daya pada Honda Vario 125cc PGM FI dengan memvariasikan massa roller 9 gram, 10 gram, 12 gram, 15 gram, dan 18 gram dengan variasi putaran mesin $2500 \mathrm{rpm}, 5000 \mathrm{rpm}$ dan $8500 \mathrm{rpm}$. Alat yang digunakan dalam proses pengambilan data penelitian adalah dynotest.

Prosedur penelitian ini dimulai dengan persiapan alat dan bahan, kemudian menyiapkan variabel roller dan spring yang akan digunakan pada sepeda motor Honda Vario 125. Selanjutnya adalah pengujian torsi dan daya, pengujian dilakukan di Hyperspeed dengan menggunakan Dynamometer. Hasil pengujian yang diambil adalah berupa torsi dan daya. Pengambilan data dengan variasi putaran mesin 2500 rpm, 5000 rpm, dan 8500 rpm dilakukan 3 kali pengujian dalam satu siklus secara berurutan.

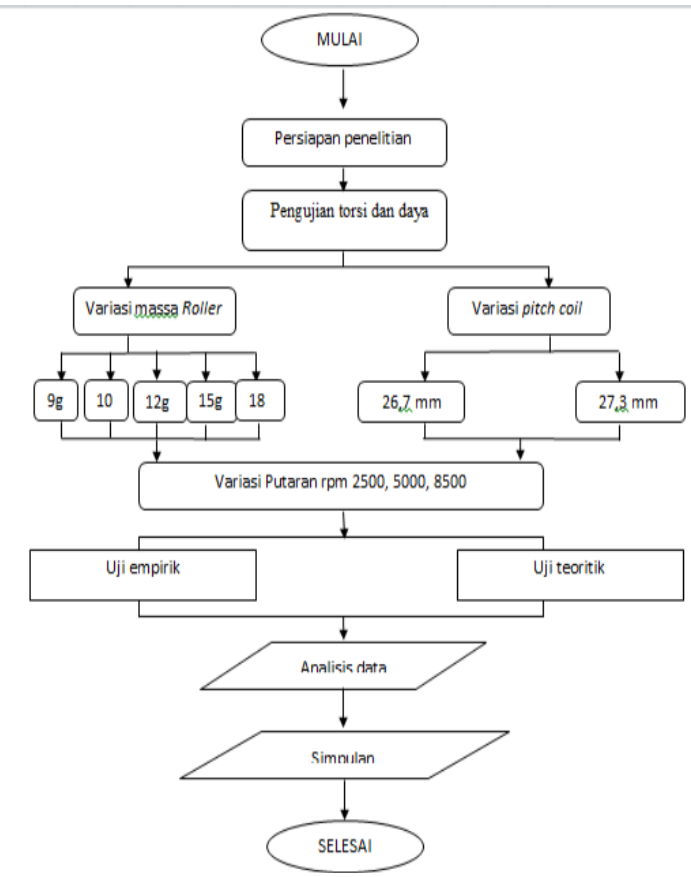

Gambar 1. Diagram alir penelitian 


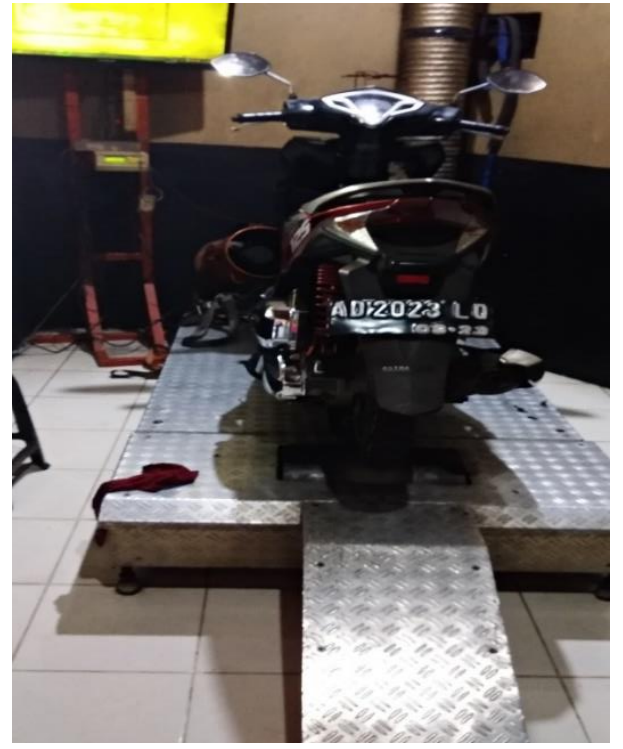

Gambar 2. Proses pengambilan data torsi dan daya

\section{HASIL DAN PEMBAHASAN}

Pengujian dilakukan sebanyak tiga kali pada setiap variabel. Berikut data hasil pengujian performa mesin yang meliputi torsi dan daya.

a. Torsi

Data hasil analisis teoritis

Berikut adalah data hasil perhitungan secara teoritis performa mesin meliputi torsi, daya, dan analisis gaya sentrifugal pada roller CVT.

Tabel 1. Data hasil analisis teoritis torsi pegas pitch coil $26,7 \mathrm{~mm}$.

\begin{tabular}{|c|c|c|c|c|c|}
\hline \multirow{2}{*}{$\begin{array}{l}\text { Putaran } \\
\text { mesin }\end{array}$} & \multicolumn{5}{|c|}{ Torsi } \\
\hline & $\begin{array}{c}\text { Roller } 9 \\
\text { gram }\end{array}$ & $\begin{array}{c}\text { Roller } 10 \\
\text { gram }\end{array}$ & $\begin{array}{c}\text { Roller } 12 \\
\text { gram }\end{array}$ & $\begin{array}{c}\text { Roller } 15 \\
\text { gram }\end{array}$ & $\begin{array}{c}\text { Roller } 18 \\
\text { gram }\end{array}$ \\
\hline \multirow[t]{6}{*}{$2500 \mathrm{pm}$} & 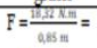 & $\mathrm{F}=\frac{1, \mathrm{MNN}}{0.85 \mathrm{~m}}=$ & 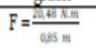 & $\mathrm{F}=\frac{2.5 \mathrm{~N} N \mathrm{Nin}}{0.45 \mathrm{mi}}=$ & 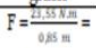 \\
\hline & $21,55 \mathrm{~N}$ & $22,92 \mathrm{~N}$ & $=24,09 \mathrm{~N}$ & $26,54 \mathrm{~N}$ & $27,70 \mathrm{~N}$ \\
\hline & sehingeg & sehingeg & sehingga & sehingen & sehingga \\
\hline & $\mathrm{T}=21,55 \mathrm{Nx}$ & $\mathrm{T}=22,92 \mathrm{Nx}$ & $\mathrm{T}=24,09 \mathrm{~N}$ & $\mathrm{~T}=26,54 \mathrm{Nx}$ & $\mathrm{T}=27,70 \mathrm{~N}$ \\
\hline & $0,85 \mathrm{~m}$ & $0,85 \mathrm{~m}$ & $\mathrm{x} 0,85 \mathrm{~m}$ & $0,85 \mathrm{~m}$ & $\times 0,85 \mathrm{~m}$ \\
\hline & $=18,32 \mathrm{Nm}$ & $=19,49 \mathrm{Nm}$ & $=20,48 \mathrm{~N} . \mathrm{m}$ & $=22,56 \mathrm{N.m}$ & $=23,55 \mathrm{X}, \mathrm{w}$ \\
\hline
\end{tabular}

Tabel 2. Data hasil analisis teoritis torsi pegas pitch coil $27,3 \mathrm{~mm}$.

\begin{tabular}{|c|c|c|c|c|c|}
\hline \multirow{2}{*}{$\begin{array}{l}\text { Putaran } \\
\text { mesin }\end{array}$} & \multicolumn{5}{|c|}{ Torsi } \\
\hline & $\begin{array}{l}\text { Roller } 9 \\
\text { gram }\end{array}$ & Roller 10 & Roller 12 & Roller 15 & $\begin{array}{c}\text { Roller } 18 \\
\text { gram }\end{array}$ \\
\hline \multirow[t]{6}{*}{$2500 \mathrm{pm}$} & 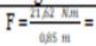 & $\mathrm{F}=\frac{1.5 \mathrm{Nm}}{0.85 \mathrm{~m}}=$ & 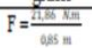 & 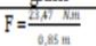 & $\mathrm{F}=\frac{4.5 \mathrm{kn}}{0.05 \mathrm{~m}}$ \\
\hline & $25.43 \mathrm{~N}$ & $23.36 \mathrm{~N}$ & $=25,71 \mathrm{~N}$ & $=27.61 \mathrm{~N}$ & $=28.82 \mathrm{~N}$ \\
\hline & sehingga & sehingeg & sehingga & sehingga & sehingg T \\
\hline & $\mathrm{T}=25,43 \mathrm{~N}$ & $\mathrm{~T}=23,36 \mathrm{Nx}$ & $\mathrm{T}=25,71 \mathrm{~N}$ & $\mathrm{~T}=27,61 \mathrm{Nx}$ & $=28,82 \mathrm{Nx}$ \\
\hline & $\mathrm{x} 0,85 \mathrm{~m}$ & $0,85 \mathrm{~m}$ & $\times 0,85 \mathrm{~m}$ & $0,85 \mathrm{~m}$ & $0,85 \mathrm{~m}$ \\
\hline & $=? 1,6 ? \mathrm{~N} \cdot \mathrm{m}$ & $=19,86 \mathrm{Nm}$ & $=21,86 \mathrm{Nm}$ & $=23,47 \mathrm{Nm}$ & $=24,50 \mathrm{Nm}$ \\
\hline
\end{tabular}

Data hasil pengujian empiric Tabel 3. Torsi yang dihasilkan dengan menggunakan spring jarak pitch coil $26,7 \mathrm{~mm}$ dan variasi roller.

\begin{tabular}{cccccc}
\hline Putaran & \multicolumn{5}{c}{ Torsi Nm) } \\
\cline { 2 - 6 } mesin & Roller' & Roller 10 & Roller 12 & Roller 15 & Roller 18 \\
& gram & gram & gram & gam & gam \\
\hline 2500 & 18.32 & 19.49 & 20.48 & 22.56 & 23.55 \\
5000 & 15.14 & 15.14 & 14.33 & 13.11 & 12.82 \\
8500 & 7.19 & 7.59 & 7.29 & 7.41 & 6.90 \\
\hline
\end{tabular}

Tabel 4. Torsi yang dihasilkan dengan menggunakan spring jarak pitch coil $27,3 \mathrm{~mm}$ dan variasi roller.

\begin{tabular}{cccccc}
\hline Putaran & \multicolumn{5}{c}{ Torsi (Nm) } \\
\cline { 2 - 6 } mesin & Roller 9 & Roller 10 & Roller 12 & Roller 15 & Roller 18 \\
& gam & gram & gram & gram & gram \\
\hline 2500 & 21.62 & 19.86 & 21.86 & 23.47 & 24.50 \\
5000 & 14.44 & 15.35 & 14.91 & 12.80 & 12.92 \\
8500 & 7.20 & 7.65 & 7.23 & 7.43 & 7.20 \\
\hline
\end{tabular}

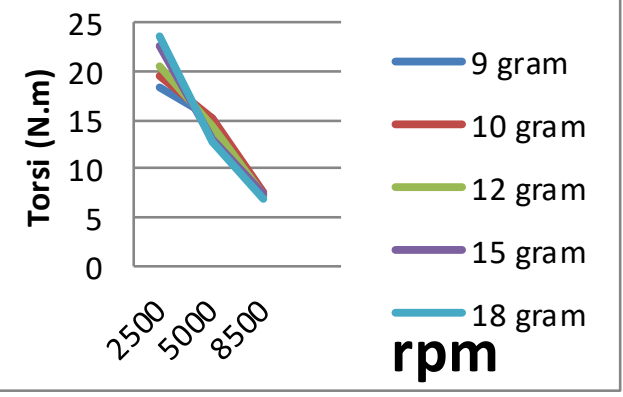

Gambar 3. Grafik perbandingan torsi terhadap putaran mesin dengan menggunakan variasi roller dan pegas pitch coil $26,7 \mathrm{~mm}$ 
Grafik 3 diatas menunjukan bahwa torsi terbesar didapatkan pada penggunaan roller 18 gram pada putaran mesin $2500 \mathrm{rpm}$ yaitu sebesar 23,55 N.m, sedangkan daya terendah pada penggunaan roller 18 gram pada putaran mesin $8500 \mathrm{rpm}$ sebesar 6,90 N.m.

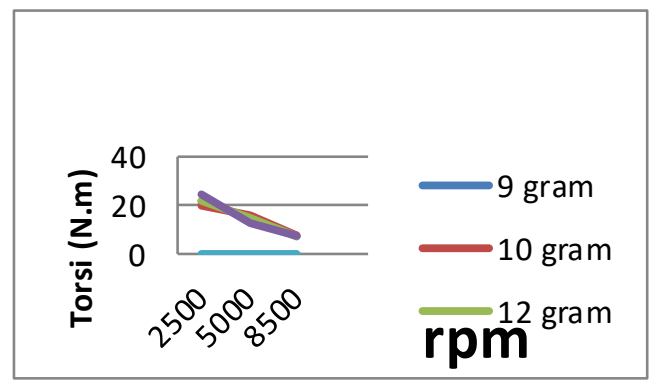

Gambar 4. Grafik perbandingan torsi terhadap putaran mesin dengan menggunakan variasi roller dan pegas pitch coil $26,7 \mathrm{~mm}$.

Grafik 4 diatas menunjukan bahwa torsi terbesar didapatkan pada penggunaan roller 15 gram pada putaran mesin $2500 \mathrm{rpm}$ yaitu sebesar 24,50 N.m, sedangkan daya terendah pada penggunaan roller 18 gram pada putaran mesin $8500 \mathrm{rpm}$ sebesar 7,20 N.m.

b. Daya

Data hasil pengujian teoritis

Tabel 5. Data hasil analisis teoritis daya pegas pitch coil $26,7 \mathrm{~mm}$.

\begin{tabular}{cccccc}
\hline $\begin{array}{c}\text { Putaran } \\
\text { mesin }\end{array}$ & \multicolumn{5}{c}{ Daya hp (kw) } \\
\cline { 2 - 6 } & $\begin{array}{c}\text { Roller 9 } \\
\text { gam }\end{array}$ & $\begin{array}{c}\text { Roller 10 } \\
\text { gam }\end{array}$ & $\begin{array}{c}\text { Roller 12 } \\
\text { gam }\end{array}$ & $\begin{array}{c}\text { Roller 15 } \\
\text { gram }\end{array}$ & $\begin{array}{c}\text { Roller 18 } \\
\text { gam }\end{array}$ \\
\hline $2500 \mathrm{~mm}$ & $4,79 \mathrm{kw}$ & $5,09 \mathrm{kw}$ & $5,35 \mathrm{kw}$ & $5,9 \mathrm{kw}$ & $6,16 \mathrm{kw}$ \\
$5000 \mathrm{~mm}$ & $7,95 \mathrm{kw}$ & $7,92 \mathrm{kw}$ & $7,49 \mathrm{kw}$ & $6,86 \mathrm{kw}$ & $6,7 \mathrm{kw}$ \\
$8500 \mathrm{~mm}$ & $6,39 \mathrm{kw}$ & $6,75 \mathrm{kw}$ & $6,48 \mathrm{kw}$ & $6,59 \mathrm{kw}$ & $6,13 \mathrm{kw}$ \\
\hline
\end{tabular}

Tabel 6. Data hasil analisis teoritis daya pegas pitch coil $27,3 \mathrm{~mm}$.

\begin{tabular}{cccccc}
\hline $\begin{array}{c}\text { Putaran } \\
\text { mesin }\end{array}$ & \multicolumn{5}{c}{ Daya hp (kw) } \\
\cline { 2 - 6 } & $\begin{array}{c}\text { Roller 9 } \\
\text { gam }\end{array}$ & $\begin{array}{c}\text { Roller 10 } \\
\text { gam }\end{array}$ & $\begin{array}{c}\text { Roller 12 } \\
\text { gram }\end{array}$ & $\begin{array}{c}\text { Roller 15 } \\
\text { gam }\end{array}$ & $\begin{array}{c}\text { Roller 18 } \\
\text { gam }\end{array}$ \\
\hline $2500 \mathrm{~mm}$ & $5,65 \mathrm{kw}$ & $5,19 \mathrm{kw}$ & $5,71 \mathrm{kw}$ & $6,14 \mathrm{kw}$ & $6,41 \mathrm{kw}$ \\
$5000 \mathrm{~mm}$ & $7,55 \mathrm{kw}$ & $8,03 \mathrm{kw}$ & $7,8 \mathrm{kw}$ & $6,69 \mathrm{kw}$ & $6,76 \mathrm{kw}$ \\
$8500 \mathrm{~mm}$ & $6,4 \mathrm{kw}$ & $6,8 \mathrm{kw}$ & $6,43 \mathrm{kw}$ & $6,61 \mathrm{kw}$ & $6,4 \mathrm{kw}$ \\
\hline
\end{tabular}

Table 7. daya yang dihasilkan dengan menggunakan spring jarak pitch coil $26,7 \mathrm{~mm}$ dan variasi roller.

\begin{tabular}{cccccc}
\hline Putaran & \multicolumn{5}{c}{ Daya (hp) } \\
\cline { 2 - 6 } mesin & $\begin{array}{c}\text { Roller 9 } \\
\text { gram }\end{array}$ & $\begin{array}{c}\text { Roller 10 } \\
\text { gam }\end{array}$ & $\begin{array}{c}\text { Roller 12 } \\
\text { gram }\end{array}$ & $\begin{array}{c}\text { Roller 15 } \\
\text { gram }\end{array}$ & $\begin{array}{c}\text { Roller 18 } \\
\text { gram }\end{array}$ \\
\hline 2500 & 6.3 & 6.8 & 7.0 & 7.8 & 8.1 \\
5000 & 10.8 & 10.6 & 10.1 & 9.2 & 9.0 \\
8500 & 8.7 & 9.1 & 8.8 & 8.9 & 8.3 \\
\hline
\end{tabular}

Tabel 8. Daya yang dihasilkan dengan menggunakan spring jarak pitch coil $27,3 \mathrm{~mm}$ dan variasi roller.

\begin{tabular}{cccccc}
\hline $\begin{array}{c}\text { Putaran } \\
\text { mesin }\end{array}$ & \multicolumn{5}{c}{ Dava (hp) } \\
\cline { 2 - 6 } & $\begin{array}{c}\text { Roller 9 } \\
\text { gam }\end{array}$ & $\begin{array}{c}\text { Roller 10 } \\
\text { gram }\end{array}$ & $\begin{array}{c}\text { Roller 12 } \\
\text { gam }\end{array}$ & $\begin{array}{c}\text { Roller 15 } \\
\text { gam }\end{array}$ & $\begin{array}{c}\text { Roller 18 } \\
\text { gam }\end{array}$ \\
\hline 2500 & 7.4 & 6.9 & 7.5 & 8.4 & 8.1 \\
5000 & 10.1 & 10.6 & 10.5 & 9.0 & 9.1 \\
8500 & 8.7 & 9.2 & 8.7 & 9.0 & 8.7 \\
\hline
\end{tabular}

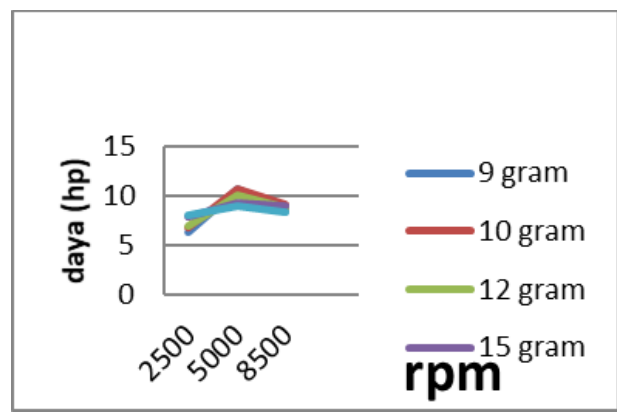

Gambar 5. Grafik perbandingan daya terhadap putaran mesin dengan menggunakan variasi roller dan pegas pitch coil $26,7 \mathrm{~mm}$.

Grafik 5 diatas menunjukan bahwa daya terbesar didapatkan pada penggunaan roller 9 gram pada putaran mesin $5000 \mathrm{rpm}$ yaitu sebesar 10,6 hp, sedangkan daya terendah pada penggunaan roller 9 gram pada putaran mesin $2500 \mathrm{rpm}$ sebesar 6,3 hp. 


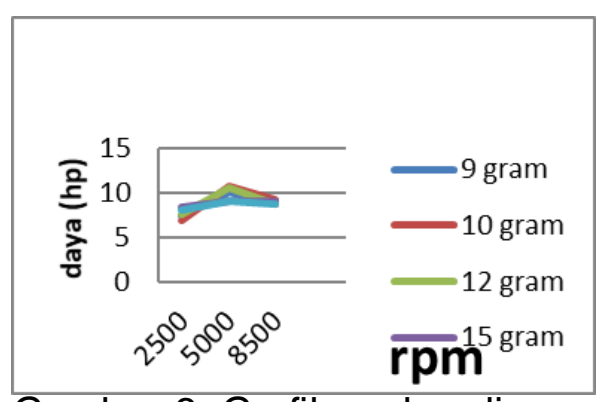

Gambar 6. Grafik perbandingan daya terhadap putaran mesin dengan menggunakan variasi rollerdan pegas pitch coil $26,7 \mathrm{~mm}$.

Grafik 6 diatas menunjukan bahwa daya terbesar didapatkan pada penggunaan roller 10 gram pada putaran mesin $5000 \mathrm{rpm}$ yaitu sebesar 10,8 hp, sedangkan daya terendah pada penggunaan roller 10 gram pada putaran mesin $2500 \mathrm{rpm}$ sebesar 6,9 hp.

Perbedaan hasil penelitian disebabkan karena perbedaan gerak sliding sheave yang diakibatkan oleh perbedaan berat roller CVT, sedangkan roller dapat bergerak karena akibat dari gaya sentrifugal. Pernyataan tersebut sependapat dengan Subandrio (2009: 21) "weight bekerja akibat adanya putaran yang tinggi dan adanya gaya sentrifugal, sehingga slider mendorong weight dan menekan sliding sheave." Kecepatan gerak sliding sheave dipengaruhi oleh berat roller, hal ini juga diperkuat oleh penelitian Hutabarat et al. (2018: 59) bahwa terdapat perbedaan hasil daya (PS) dari penggunaan variasi roller, yaitu 9 gram, 7 gram, 11 gram, mix (7\& 9 gram), serta mix (9 \& 11 gram). Gerak sliding sheave tersebut yang mempengaruhi perbedaan torsi, semakin perlahan gerak sliding sheave maka semakin besar torsi yang berpengaruh dan berbanding lurus dengan nilai daya yang dihasilkan sehingga perbedaan nilai daya hampir sama dengan nilai torsi yang dihasilkan karena keduanya saling berkaitan, dari beberapa pendapat tersebut maka dapat disimpulkan bahwa massa roller, torsi dan daya saling berkaitan.

\section{SIMPULAN}

Berdasarkan hasil penelitian dan pembahasan, dapat diambil kesimpulan sebagai berikut:

a. Dari hasil penelitian dyno test yang menggunakan variasi pegas(spring) dan variasi massa roller bahwa tidak ada pengaruh secara signifikan massa roller CVT standart dengan variasi terhadap daya dan torsi. Ada pengaruh variasi putaran mesin secara signifikan terhadap daya dan torsi dalam memvariasikan massa roller CVT.

1. Pegas CVT dengan jarak pitch coil 26,7mm mampu menghasilkan daya kendaraan terbesar dengan menggunakan roller 9 gram pada kecepatan menengah 5000 rpm senilai $10,8 \mathrm{hp}$ dan pegas dengan jarak pitch coil $27,3 \mathrm{~mm}$ menghasilkan daya kendaraan terbesar dengan menggunakan roller 10 gram pada kecepatan menengah 5000rpm senilai 10,6hp. Roller CVT dengan berat 18 gram mampu menghasilkan torsi maksimum pada penggunaan pegas 26,7 $\mathrm{mm}$ kecepatan 2500rpm senilai 23,55 N.m, maupun dengan menggunakan pegas $27,3 \mathrm{~mm}$ torsi maksimum terjadi juga pada kecepatan 2500rpm senilai 24.50 N.m. Pegas dengan jarak pitch coil $26,7 \mathrm{~mm}$ dan roller 9 gram yang mampu menghasilkan gaya dorong kendaraan terbesar pada kecepatan menengah 5000rpm 
lebih cocok digunakan untuk berakselerasi di jalan kota.

\section{SARAN}

a. Penggunaan massa roller ringan 9 gram dengan pegas $26,7 \mathrm{~mm}$ cocok digunakan untuk kendaraan vario $125 \mathrm{cc}$ yang memerlukan akselerasi dijalan rata atau perkotaan.

b. Penggunaan massa roller berat 18 gram dengan pegas $26,7 \mathrm{~mm}$ cocok digunakan untuk kendaraan vario $125 \mathrm{cc}$ yang memerlukan torsi besar dijalan tanjakan.

c. Perlu adanya pengembangan penelitian lebih lanjut yang menggunakan sepeda motor yang masih memiliki peforma maksimal dan penggunaan roller dengan jenis material berbeda sehingga penelitian diharapkan mendapat hasil yang relevan.

d. Penelitian ini dapat menjadi referensi pada peneltian lainnya yang berhubungan dengan massa roller dan pegas CVT.

\section{DAFTAR PUSTAKA}

Adityas, P. C, Sudibyo dan Basori. 2012. Pengaruh Berat Roller CVT (Continuosly Variable Transmission) dan Variasi Putaran Mesin Terhadap Torsi Pada Yamaha Mio Sporty Tahun 2007. Jurnal Nosel 1(1): 65-70.

Dharma, G, A. dan Wulandari, D. 2013. Pengaruh Pemakaian Variasi Pegas Sliding Sheave terhadap Performance Motor Honda Beat 2011. JTM, Vol. 02. No. $01: 126-131$

Hidayat, W. 2015.Trans-Matic Pemindah Daya Kendaraan, Jakarta: PT Rineka Cipta.

Hutabarat, H. Darlius dan Zulherman. 2018. Pengaruh Variasi Berat Roller CVT dan RPM terhadap Daya pada
Yamaha Soul Gt 115cc. Jurnal Pendidikan Teknik Mesin. Vol 5. No. 1. :55-61

Subandrio. 2009. Merawat dan Memperbaiki Sepeda Motor Matic. Jakarta: Kawan Pustaka. 